\title{
Surgical outcome of percutaneous transhepatic gallbladder drainage in acute cholecystitis: Ten years' experience at a tertiary care centre
}

\author{
Szabolcs Ábrahám ${ }^{1,7}$ (Illés Tóth ${ }^{1} \cdot$ Ria Benkö $^{2,3,4} \cdot$ Mária Matuz $^{2,3} \cdot$ Gabriella Kovács $^{5} \cdot$ Zita Morvay $^{5} \cdot$ András Nagy $^{5}$. \\ Aurél Ottlakán ${ }^{1} \cdot$ László Czakó $^{6} \cdot$ Zoltán Szepes $^{6} \cdot$ Dániel Váczi · András Négyessy $^{1} \cdot$ Attila Paszt · Zsolt Simonka ${ }^{1}$. \\ András Petri ${ }^{1}$. György Lázár ${ }^{1}$
}

Received: 8 February 2021 / Accepted: 18 May 2021 / Published online: 20 August 2021

(c) The Author(s) 2021

\begin{abstract}
Background Percutaneous transhepatic gallbladder drainage (PTGBD) plays an important role in the treatment of elderly patients and/or patients in poor health with acute cholecystitis (AC). The primary aim of this study is to determine how these factors influence the clinical outcome of PTGBD. Moreover, we assessed the timing and results of subsequent cholecystectomies.

Patients and Methods We retrospectively examined the results of 162 patients undergoing PTGBD between 2010 and 2020 (male-female ratio: $51.23 \%$ vs. $48.77 \%$; mean age: $71.43 \pm 13.22$ years). Patient's performance status and intervention outcomes were assessed with clinical success rates (CSR) and in-hospital mortality. The conversion rate (CR) of possible urgent or delayed, elective laparoscopic cholecystectomies (LC) after PTGBD were analysed.

Results PTGBD was the definitive treatment in $42.18 \%$ of patients, while it was a bridging therapy prior to cholecystectomy (CCY) for the other patients. CSR was $87.97 \%$, it was only $64.29 \%$ in grade III AC. In $9.87 \%$ of the cases, urgent LC was necessary after PTGBD, and its conversion rate was approximately equal to that of elective LC (18.18 vs. $17.46 \%$, respectively, $p=0.2217$ ). Overall, the post-PTGBD in-hospital mortality was $11.72 \%$, while the same figure was $0 \%$ for grade I AC, $7.41 \%$ for grade II and $40.91 \%$ for grade III. Based on logistic regression analyses, in-hospital mortality (OR 6.07; CI 1.79-20.56), clinical progression (OR 7.62; CI 2.64-22.05) and the need for emergency CCY (OR 14.75; CI 3.07-70.81) were mostly determined by AC severity grade.

Conclusion PTGBD is an easy-to-perform intervention with promising clinical success rates in the treatment of acute cholecystitis. After PTGBD, the level of gallbladder inflammation played a decisive role in the course of AC. In a severe, grade III inflammation, we have to consider low CSR and high mortality.
\end{abstract}

Keywords Acute cholecystitis $\cdot$ Laparoscopic cholecystectomy $\cdot$ Mortality $\cdot$ Conversion rate $\cdot$ Percutaneous cholecystostomy

Percutaneous transhepatic gallbladder drainage (PTGBD) is an invasive radiological method that has been used from the

Szabolcs Ábrahám

abraham.szabolcs@med.u-szeged.hu

1 Department of Surgery, University of Szeged, Szeged, Hungary

2 Department of Clinical Pharmacy, University of Szeged, Szeged, Hungary

3 Central Pharmacy and Emergency Care Department, University of Szeged, Szeged, Hungary

4 Central Pharmacy Department, University of Szeged, Szeged, Hungary early 1980s [1-5], and it is now an essential part of treatment for acute cholecystitis (AC). Ultrasound (US)-guided

5 Radiology Department, University of Szeged, Szeged, Hungary

6 First Department of Internal Medicine, University of Szeged, Szeged, Hungary

7 Department of Surgery, University of Szeged, Albert Szent-Györgyi Health Centre, Semmelweis u. 8., 6725 Szeged, Hungary 
PTGBD is a technically easy-to-perform method with a relatively high clinical success rate. According to the literature, the technical success rate of PTGBD is approximately 95\% during AC treatment, whereas the clinical success rate ranges between $56 \%$ and $100 \%$ [6-10].

Nowadays, the Tokyo Guidelines 2018 recommendations form the standard in treating AC [11]. Compared to the Tokyo Guidelines 2013 (TG13) [12], the 2018 (TG18) version further clarifies the role of PTGBD in treating AC. In grade II, moderate AC urgent/early laparoscopic cholecystectomy (LC) is the primary therapy of choice. If the patient is unsuitable for surgery due to his general condition and/or does not respond adequately to antibiotics and general supportive care, PTGBD becomes necessary. According to the Tokyo Guidelines 2018, the indication for PTGBD in grade III AC is determined by the patient's performance status (Charlson comorbidity index (CCI) [13], the American Society of Anesthesiologists (ASA) physical status [14]) based on negative predictive factors (jaundice and neurological and respiratory dysfunction) and favourable organ system failure (FOSF; cardiovascular and renal organ failure).

Complicated AC is a relatively high-mortality disease [15]. Emergency or early LC is a surgery with great technical difficulties, and it is accompanied by a high conversion rate $[16$, 17], a chance of biliary duct injury and high mortality [8]. The aim of PTGBD is to provide an alternative treatment option to high-risk patients with moderate (grade II) or severe (grade III) AC. In some cases, when the patient is not even fit for elective surgery, PTGBD can provide a definitive therapeutic solution. However, most of the time, it serves as a bridging therapy before elective LC.

Managing $\mathrm{AC}$ is a multidisciplinary task which aims to treat the disease most effectively by avoiding septic complications. In many cases, despite the detailed recommendations in the guidelines, it is difficult to decide which treatment strategy is the most ideal for the patient. Nevertheless, whatever treatment or path we choose, the objective is to avoid complications and decrease mortality and thus to increase survival.

The success of AC treatment may be influenced by several factors, such as general condition, comorbidities, patient age and level of gallbladder inflammation. The aim of this study is to ascertain how these factors influence the success of PTGBD, the timing of subsequent cholecystectomies and their outcomes. In addition, it is necessary to further clarify the role and place of PTGBD in the complex treatment algorithm of AC.

\section{Materials and methods}

Ethical permission $(81 / 2020$-SZTE) for the study was obtained from the Regional Human Biomedical Research Ethics Committee of the University of Szeged.
We retrospectively examined abdominal ultrasound (US)guided PTGBD interventions performed with AC indication at the University of Szeged for a ten-year period from 2010 to 2020. Patients who underwent percutaneous transhepatic gallbladder aspiration or endosonography-guided gallbladder drainage or computer tomography (CT)-guided PTGBD were excluded from the study. We did these exclusions to provide a homogenous study population in terms of the used interventional radiology method (i.e. only ultrasoundguided PTGBD). Moreover, nine patients who had a history of hepato-pancreatic-biliary malignancy prior to PTGBD or who were diagnosed with it after the procedure as well as patients who received further treatment after PTGBD outside the University of Szeged were excluded. After exclusions, data were analysed from 162 patients with PTGBD.

In radiologically confirmed AC patients, the TG13 and TG18 recommendations were followed when indicating PTGBD [18, 12, 11].

The severity of inflammation was determined retrospectively based on the TG18/TG13 severity grading for acute cholecystitis defined in the Tokyo Guidelines 2018 [19]. The severity of AC-related inflammation in each patient was classified as grade I (mild), II (moderate) and III (severe). Based on abdominal ultrasound, the indications for PTGBD were grouped as follows: acute acalculous cholecystitis (AAC), acute calculous cholecystitis (ACC), empyema vesicae felleae (EVF), hydrops vesicae felleae (HVF) and covered perforated cholecystitis (PC) [20].

Sex and age group (18-65 years or over 65 years) distribution and patient's performance status were determined: the ASA score (I-VI) was determined for each patient, and patients were classified into three groups based on the Charlson comorbidity index (CCI) as follows: CCI $0, \mathrm{CCI} 1-3$ and over CCI 4. Based on the time elapsed between the onset of complaints and PTGBD, patients were grouped into three categories ( $0-72 \mathrm{~h}$, three days to one week and beyond one week).

The average duration of drain presence after PTGBD was assessed. The need for endoscopic retrograde cholangiopancreatography (ERCP) during hospitalization and after hospital discharge time over an average were followed for a five-year period. The indications of ERCP (non-decreasing biliary excretion, sepsis (including cholangiosepsis), biliary obstruction (BO)) and its results were assessed. The need for urgent $\mathrm{CCY}$ due to the rapidly deteriorating clinical condition of the patients after PTGBD was determined.

Three endpoints were determined in terms of clinical and surgical outcomes of PTGBD. The clinical success rate (CSR) of PTGBD (number of clinically regressive cases after PTGBD X 100/[total number of PTGBD procedures - number of technically unsuccessful procedures]) was calculated. Clinical regression was determined by remission of patient's symptoms, improvement in inflammatory markers 
(leukocyte count, CRP and PCT) and radiological (US or abdominal CT) regression. As a routine practice, we followed up the patients with control abdominal ultrasound after the PTGBD everyday/every second day or rarely with CT. We check the position of the inserted tube/drain and the possible regression or progression of the gall bladder inflammation (thickness of the gallbladder wall, pericholecystic fluid, etc.).

CSR was assessed according to different patient sexes, age groups, TG18/13 AC severity grades, CCI and time elapsed between the onset of complaints and hospital admission were analysed.

In addition to CSR, the technical success rate (TSR) of PTGBD (technically successful procedure $\times 100 /$ total procedures) was also calculated. We interpreted invasive radiological interventions where we observed drain failure (occlusion, drain displacement, improper tube positioning, etc.) as technically unsuccessful PTGBD.

As a second endpoint in terms of clinical outcome, we analysed the proportion of CCYs after PTGBD and the need for possible emergency surgeries. We examined the proportion of PTGBD reported as final therapy (no need for CCY) and as a bridging therapy (i.e. the percentage of elective CCY performed in patients who responded well to drainage). All elective CCY surgeries performed after hospital discharge during an average five-year follow-up period were analysed. In terms of surgical outcome, we determined the proportion of primary open cholecystectomy, laparoscopic cholecystectomy (LC) and conversion after LC during both emergency and elective CCY surgery. Based on the above, the conversion rate (CR) of LCs (number of converted LCs $\times 100$ /[number of total surgeries - number of primary open cholecystectomies] and the laparoscopic success rate (LSR) (number of LCs/numbers of total surgeries) were calculated. Elective surgeries were further divided into two groups according to the time elapsed between PTGBD and the CCY surgery (performed between three to six weeks and after six weeks). In these groups, the previous parameters (CR and LSR) were also determined. Possible bile duct injury during CCY was examined as well.

Finally, as a third endpoint in terms of clinical and surgical outcome, we calculated the in-hospital mortality and procedure mortality (directly related to PTGBD, such as bleeding, embolism and other organ injury). We further analysed in-hospital mortality in relation to different patient or intervention characteristics.

\section{Statistical analysis}

Detailed descriptive statistics for continuous and categorical variables were reported. Welch's t-test, one-way ANOVA, Pearson's chi-squared test or Fischer's exact test were used for the univariate analysis, as appropriate. We tested the association between negative patient outcomes (in-hospital mortality, clinical progression and emergency cholecystectomy) and patient's performance status or ACC severity with a univariate method followed by logistic regression. Statistical analysis was performed using R 3.5.1.

\section{Results}

Among the 162 patients who underwent PTGBD within the ten-year investigation period, there were nearly equal proportions of men and women $(51.23 \%$ vs. $48.77 \%)$. Their mean age was $71.43 \pm 13.22$ years, and the majority of them $(71.60 \%)$ was over 65 years of age. It should be noted that the age of patients who died after PTGBD during in-hospital time was significantly higher compared to the survival group (76.82 $\pm 9.77 v s .71 .16 \pm 12.98$ years). Mean age was significantly higher in more severe inflammation (grade I: $63.14 \pm 16.52$ years; grade II: $70.79 \pm 13.14$ years; grade III: $78.89 \pm 7.22$ years) and in patients who required emergency CCY than those who had elective CCY $(74.75 \pm 13.13$ vs. $68.00 \pm 11.05$ years). In cases where no surgical procedure was performed, PTGBD served as definitive therapy. Mean age of these patients was $73.39 \pm 15.39$ years.

In addition to the high mean age, the majority of the PTGBD patients had a CCI above 4 (65.38\%). The distribution of the AC severity grade was the following: grade I: 8.8\%; grade II: $73.6 \%$; and grade III: 17.6. Most frequently, PTGBD was called for due to abdominal US-confirmed ACC in $33.95 \%$ of the cases, covered cholecystitis perforation in $27.16 \%$ and AAC in $5.56 \%$ (Table 1). Hospital admission occurred between $72 \mathrm{~h}$ and one week after the onset of complaints in almost half of the cases (45.6\%). In general, PTGBD was performed within $72 \mathrm{~h}$ in $39.71 \%$ of the cases, and beyond one week in $14.71 \%$. TSR for PTGBD was $97.53 \%$, procedure mortality was $0 \%$, and CSR was $87.97 \%$. The drain inserted was removed $11.65 \pm 7.57$ days after PTGBD on average. After PTGBD, 62 (42.18\%) did not undergo subsequent $\mathrm{CCY}$; drainage therefore proved to be a definitive therapy. 69 patients (46.94) had CCY, and 16 patients $(10.88 \%)$ had emergency surgery due to the deteriorating clinical condition and progression. The mean timing of elective surgeries was $13.57 \pm 10.89$ weeks after PTGBD (Table 1).

CSR of PTGBD deteriorated significantly in patients over 65 years and in parallel with the increasing severity of the inflammation (Table 2). While basically all patients under 65 years of age experienced clinical regression, CSR was only $83.62 \%$ in patients over 65 years. In grade I inflammation, we also had complete clinical success in all patients; however, CRS was 92.04 in grade II and only $64.29 \%$ in grade III. The clinical regression varied inversely with the ASA score and a similar tendency could 
Table 1 General patient and intervention characteristics

\begin{tabular}{|c|c|c|c|c|c|}
\hline & & $N$ & $\%$ & Mean \pm SD & Min-Max \\
\hline \multirow[t]{3}{*}{ Age (years) } & $30-65$ & 46 & 28.4 & & \\
\hline & $65+$ & 116 & 71.6 & & \\
\hline & Total & 162 & 100 & $71.43 \pm 13.22$ & $33-95$ \\
\hline \multirow[t]{3}{*}{$\operatorname{Sex}$} & Female & 79 & 48.77 & & \\
\hline & Male & 83 & 51.23 & & \\
\hline & Total & 162 & 100 & & \\
\hline \multirow[t]{5}{*}{ ASA score } & 1 & 16 & 10.13 & & \\
\hline & 2 & 65 & 41.14 & & \\
\hline & 3 & 54 & 34.18 & & \\
\hline & 4 & 23 & 14.56 & & \\
\hline & $N A$ & 4 & & & \\
\hline \multirow[t]{5}{*}{$C C I$} & CCI 0 & 8 & 5.13 & & \\
\hline & CCI 1-3 & 46 & 29.49 & & \\
\hline & $\mathrm{CCI} 4+$ & 102 & 65.38 & & \\
\hline & Total & 156 & 100 & $4.21 \pm 2.25$ & $0-10$ \\
\hline & $N A$ & 6 & & & \\
\hline \multirow[t]{4}{*}{ Time frame (between onset of complaints and hospital admission) } & $0-72 \mathrm{~h}$ & 54 & 39.71 & & \\
\hline & $72 \mathrm{~h}-1$ week & 62 & 45.59 & & \\
\hline & Over 1 week & 20 & 14.71 & & \\
\hline & $N A$ & 26 & & & \\
\hline \multirow[t]{5}{*}{ Indication of PTGBD based on abdominal US N=140;100\% } & AAC & 9 & 5.56 & & \\
\hline & ACC & 55 & 33.95 & & \\
\hline & EVF & 17 & 10.49 & & \\
\hline & HVF & 37 & 22.84 & & \\
\hline & $\mathrm{PC}$ & 44 & 27.16 & & \\
\hline \multirow[t]{4}{*}{ AC severity grade (TG18/TG13) } & I & 14 & 8.81 & & \\
\hline & II & 117 & 73.58 & & \\
\hline & III & 28 & 17.61 & & \\
\hline & $N A$ & 3 & & & \\
\hline$P T G B D$ TSR N=162100\% & & & 97.53 & & \\
\hline$P T G B D C S R N=162100 \%$ & & & 87.97 & & \\
\hline \multirow[t]{2}{*}{ Time of drain removal after PTGBD (days) } & & 88 & & $11.65 \pm 7.57$ & $1-42$ \\
\hline & $N A$ & 76 & & & \\
\hline \multirow[t]{2}{*}{ Mortality after PTGBD } & Procedure mortality & 0 & 0 & & \\
\hline & In-hospital mortality & 17 & 11.72 & & \\
\hline \multirow[t]{4}{*}{ ERCP after PTGBD } & During hospital stay & 21 & 13.46 & & \\
\hline & After hospital discharge & 4 & 2.56 & & \\
\hline & There was no ERCP & 131 & 83.97 & & \\
\hline & $N A$ & 6 & & & \\
\hline \multirow[t]{3}{*}{$C C Y$ after $P T G B D$} & Emergency CCY & 16 & 10.88 & & \\
\hline & Elective CCY & 69 & 46.94 & & \\
\hline & There was no surgery & 62 & 42.18 & & \\
\hline$B D I$ during $C C Y$ after $P T G B D$ & & 1 & 1.17 & & \\
\hline \multirow[t]{4}{*}{ Time interval between PTGBD and CCY } & Emergency (days) & 16 & 19.05 & $5.50 \pm 12.56$ & $0-52$ \\
\hline & Elective (weeks) & 68 & 80.95 & $13.57 \pm 10.89$ & $2-67$ \\
\hline & Total & 84 & 100 & $11.24 \pm 10.92$ & $0-67$ \\
\hline & $N A$ & 1 & & & \\
\hline
\end{tabular}

$A C$ Acute cholecystitis, $A A C$ Acute acalculous cholecystitis, $A C C$ Acute calculous cholecystitis, $B D I$ Bile duct injury, $C C Y$ Cholecystectomy, CSR Clinical success rate, ERCP Endoscopic retrograde cholangiopancreatography, EVF Empyema vesicae felleae, $H V F$ Hydrops vesicae felleae, NA No data, PC Covered perforated cholecyst, TSR Technical success rate, TG13/18 Tokyo Guidelines 2013 and 2018, US Ultrasound 
Table 2 Indications and timing of endoscopic retrograde cholangiopancreatography (ERCP) after percutaneous transhepatic gallbladder drainage (PTGBD)

\begin{tabular}{llll}
\hline & ERCP indication & ERCP outcome & $N$ \\
\hline During in-hospital stay & Non-decreasing biliary excretion & BO: CBDS & 5 \\
$N=20 ; 83.33 \%$ & $N=12 ; 50.00 \%$ & BO: Juxtapapillary diverticulum & 2 \\
& & BO: SOD & 2 \\
& & BO: Sclerosis of Vater's papilla & 1 \\
& & Irregular pancreatic anatomy & 1 \\
& & BO: Mirizzi syndrome & 1 \\
& Cholangiosepsis & BO: CBDS & 2 \\
& & BO: Duodenal stenosis & 1 \\
& & BO: Biliary stent obstruction & 1 \\
& Increased biliary obstruction enzymes & BO: Juxtapapillary diverticulum & 2 \\
& N=3; 12.50\% & BO: CBDS & 1 \\
After hospital discharge & Increased biliary obstruction enzymes & BO: CBDS & 1 \\
$N=4 ; 16.67 \%$ & Cholangiosepsis & BO: CBDS & 2 \\
& Non-decreasing biliary excretion & Intrahepatic minor BDI & 1 \\
Total & & & 1 \\
& & & 24 \\
\hline
\end{tabular}

$B D I$ Bile duct injury, $B O$ Biliary obstruction, $C B D S$ Common bile duct stone, $N A$ No data, SOD Sphincter of Oddi dysfunction be observed for CCI; CSR was $100 \%$ for CCI $0,88.37 \%$ for CCI $1-3$ and $86.96 \%$ for CCI $4+$. There was no significant difference in CSR in relation to time elapsed between the onset of complaints and hospital admission (see Table 3).

After PTGBD, ERCP was necessary in $15.43 \%$ of the cases (25 cases) (Table 2). The most common indication for ERCP was in cases, where no reduction in bile flow through the inserted gallbladder drain was seen. Irrespective of the indication for ERCP, choledocholithiasis was confirmed in $40 \%$ of the cases (Table 2).

Comparing emergency and elective CCY surgeries after PTGBD in terms of LSR and CR (Table 4), the proportion of primary open cholecystectomies in elective surgeries was much lower $(5 / 16(7.24 \%)$ vs. 5/69 (31.25\%)). The CR of elective LCs (17.46\%) was similar to that of emergency LCs $(18.18 \%)$.

If we further analyse elective and emergency CCYs (Table 5), it can be seen that emergency CCYs were mainly performed in older patients with higher CCI or more severe AC.

In addition to the $0 \%$ procedure mortality directly associated with the PTGBD intervention, in-hospital mortality was $11.72 \%$ (Table 6 ). There was no significant difference in mortality between male and female patients; however, mortality showed a corresponding increase with the increasing score for both ASA score and CCI. The most prominent mortality was observed in AAC cases. In this scenario, five out of nine patients died with an in-hospital mortality of $55.56 \%$, while mortality was only $6.00 \%$ for ACC. Mortality after elective surgery was $0 \%$; however, if emergency CCY was required after PTGBD, we lost $14.29 \%$ of the patients.

The logistic regression (Table 7) showed that the severity of AC inflammation had the highest odds for emergency CCY (OR 14.75; CI 3.07-70.81). The degree of inflammation also had a significant effect on clinical progression (OR 7.62; $\mathrm{Cl} 2.64-22.05$ ) and on in-hospital mortality (OR 6.07; CI 1.79-20.56). CCI had a significant odds ratio only for inhospital mortality (similarly to the results of the univariate analysis).

\section{Discussion}

Therapy of AC is a complex multidisciplinary task. A number of factors must be considered to make a therapeutic decision. According to the Tokyo Guidelines 2018 recommendations, we should consider the patient's age, general condition, comorbidities, the beginning of his or her complaints and the severity of the gallbladder inflammation [11].

US-guided PTGBD has been used for almost four decades and nowadays plays an important role in emergency care for AC $[1,3,4,2,21]$. PTGBD is a relatively easy procedure with a high technical success rate, used mainly in moderate-to-severe $\mathrm{AC}$ if the patient is not fit for surgery or does not respond adequately to antibiotics and general supportive care [8]. Although a patient's advanced age is not an absolute contraindication for acute early CCY, it may still be a determinant of complex AC treatment success [22]. Our study showed that PTGBD was mainly performed in older 
Table 3 Technical success rate and clinical outcomes of percutaneous transhepatic gallbladder drainage (PTGBD) according to patient characteristics

\begin{tabular}{|c|c|c|c|c|c|c|c|c|}
\hline & & $\begin{array}{l}\text { Clinical pro- } \\
\text { gression after } \\
\text { PTGBD }\end{array}$ & $\begin{array}{l}\text { Clinical regres- } \\
\text { sion after } \\
\text { PTGBD }\end{array}$ & $\begin{array}{l}\text { Technically } \\
\text { unsuccessful } \\
\text { PTGBD }\end{array}$ & Total & TSR $\%$ & CSR $\%$ & $p^{*}$ \\
\hline Total & & 19 & 139 & 4 & 162 & 97.53 & 87.97 & \\
\hline \multirow[t]{2}{*}{ Age (years) } & $30-65$ & 0 & 42 & 4 & 46 & & 100 & 0.003926 \\
\hline & $65+$ & 19 & 97 & 0 & 116 & & 83.62 & \\
\hline \multirow[t]{2}{*}{ Sex } & Female & 11 & 65 & 3 & 79 & & 85.53 & 0.5053 \\
\hline & Male & 8 & 74 & 1 & 83 & & 90.24 & \\
\hline \multirow[t]{5}{*}{ ASA score } & 1 & 0 & 14 & 2 & 16 & & 100 & - \\
\hline & 2 & 12 & 52 & 1 & 65 & & 81.25 & \\
\hline & 3 & 4 & 49 & 1 & 54 & & 92.45 & \\
\hline & 4 & 3 & 20 & 0 & 23 & & 86.96 & \\
\hline & $N A$ & & 4 & & 4 & & & \\
\hline \multirow[t]{4}{*}{$\mathrm{CCI}$} & $\mathrm{CCI}=0$ & 0 & 7 & 1 & 8 & & 100 & 0.6372 \\
\hline & $\mathrm{CCI}=1-3$ & 5 & 38 & 3 & 46 & & 88.37 & \\
\hline & $\mathrm{CCI}=4+$ & 14 & 88 & 0 & 102 & & 86.27 & \\
\hline & $N A$ & & 6 & & 6 & & & \\
\hline \multirow{4}{*}{$\begin{array}{l}\text { Time frame (between onset of } \\
\text { complaints and hospital admis- } \\
\text { sion) }\end{array}$} & $0-72 \mathrm{~h}$ & 8 & 46 & 0 & 54 & & 85.19 & 0.8191 \\
\hline & $72 \mathrm{~h}-1$ week & 7 & 52 & 3 & 62 & & 88.14 & \\
\hline & Over 1 week & 2 & 17 & 1 & 20 & & 89.47 & \\
\hline & $N A$ & 2 & 24 & & 26 & & & \\
\hline \multirow[t]{4}{*}{ AC severity grade (TG18/TG13) } & I & 0 & 14 & 0 & 14 & & 100 & 0.0009995 \\
\hline & II & 9 & 104 & 4 & 117 & & 92.04 & \\
\hline & III & 10 & 18 & 0 & 28 & & 64.29 & \\
\hline & $N A$ & & 3 & & 3 & & & \\
\hline
\end{tabular}

AC Acute cholecystitis, NA No data (*Pearson's chi-squared test)

Table 4 Characteristics of cholecystectomies (CCY) performed after percutaneous transhepatic gallbladder drainage (PTGBD)

\begin{tabular}{|c|c|c|c|c|c|c|c|c|c|c|}
\hline & & & $\mathrm{LC}$ & Converted LC & $\begin{array}{l}\text { Primary } \\
\text { open CCY }\end{array}$ & NA & Total & $\operatorname{LSR}(\%)$ & $p^{*} \mathrm{LSR} \%$ & $\mathrm{CR}(\%)$ \\
\hline Total & & & 61 & 13 & 10 & 1 & 85 & 71.76 & - & 17.57 \\
\hline \multirow[t]{4}{*}{ CCY after PTGBD } & Emergency & & 9 & 2 & 5 & & 16 & 56.25 & 0.1367 & 18.18 \\
\hline & Planned CCY & & 52 & 11 & 5 & 1 & 69 & 75.36 & & 17.46 \\
\hline & & within 3 to 6 weeks & 5 & 1 & 1 & & 8 & 62.50 & 0.3969 & 16.67 \\
\hline & & after 6 weeks & 47 & 10 & 4 & & 61 & 77.05 & & 17.54 \\
\hline
\end{tabular}

LSR Laparoscopic success rate (number of LCs/total number of surgeries), CR Conversion rate (number of converted LCs $\times 100 /[$ total number of surgeries - number of primary open cholecystectomies]) (*Fischer's Exact Test)

patients (mean age: $71.43 \pm 13.22$ years) with AC and CSR, with $83.62 \%$ of the patients being over 65 years. Higher mean age was also observed in more severe inflammation. Consequently, it is likely that the less elderly age group is more likely to experience clinical regression, while CSR is literally $100 \%$ for patients under 65 years.

Based on our findings, grade II and grade III inflammation mainly occurred in older patients. Among a population with advanced age, a higher CCI may accompany a potentially increased mortality rate. In our study, in-hospital mortality was $15.96 \%$ in CCI 4 + patients and $0 \%$ in CCI $0-3$. Based on previous reports, AC mortality varied with the severity of the inflammation. While 30-day mortality was $1.1 \%$ in mild inflammation (grade I), it was $0.8 \%$ in moderate (grade II) and 5.4\% in severe inflammation [23]. In-hospital mortality after PTGBD was relatively high $(11.72 \%)$ in our study. High mortality after PTGBD was confirmed by a systematic review conducted by Winbladh et al., which showed $15.4 \%$ total mortality (30-day mortality or inhospital death) [8]. Dimou et al. reported 24\% in-hospital 
Table 5 The characteristics of emergency and elective cholecystectomies (CCY) performed after percutaneous transhepatic gallbladder drainage (PTGBD)

\begin{tabular}{|c|c|c|c|c|c|}
\hline & & \multirow{2}{*}{$\begin{array}{l}\text { Elective CCY } \\
\text { after PTGBD } \\
N=69(100 \%)\end{array}$} & \multirow{2}{*}{$\begin{array}{l}\text { Emergency } \\
\text { CCY after } \\
\text { PTGBD } \\
N=16(100 \%)\end{array}$} & \multirow[t]{2}{*}{ Total } & \multirow[t]{2}{*}{$P$} \\
\hline & & & & & \\
\hline \multirow[t]{2}{*}{ Age (years) } & $30-65$ & $27(39.13 \%)$ & $2(12.5 \%)$ & 29 & \multirow[t]{2}{*}{$p$ value $=0.0762$ Fisher's exact test } \\
\hline & $65+$ & $42(60.87 \%)$ & $14(87.5 \%)$ & 56 & \\
\hline \multirow[t]{2}{*}{ Sex } & Female & $29(42.03 \%)$ & $10(62.5 \%)$ & 39 & \multirow[t]{2}{*}{$p$ value $=0.1698$ Fisher's exact test } \\
\hline & Male & $40(57.97 \%)$ & $6(37.5 \%)$ & 46 & \\
\hline \multirow[t]{4}{*}{ ASA score } & 1 & $6(8.7 \%)$ & $2(12.5 \%)$ & 8 & \multirow{4}{*}{$\begin{array}{l}p \text { value }=0.7576 \text { Pearson's chi-squared test } \\
\text { with simulated } p \text { value (based on } 2000 \\
\text { replicates) }\end{array}$} \\
\hline & 2 & $37(53.62 \%)$ & $10(62.5 \%)$ & 47 & \\
\hline & 3 & $23(33.33 \%)$ & $3(18.75 \%)$ & 26 & \\
\hline & 4 & $3(4.35 \%)$ & $1(6.25 \%)$ & 4 & \\
\hline \multirow[t]{4}{*}{$\mathrm{CCI}$} & $\mathrm{CCI}=0$ & $3(4.41 \%)$ & $1(6.25 \%)$ & 4 & \multirow{4}{*}{$\begin{array}{l}p \text { value }=0.8236 \text { Pearson's chi-squared test } \\
\text { with simulated } p \text { value (based on } 2000 \\
\text { replicates) }\end{array}$} \\
\hline & $\mathrm{CCI}=1-3$ & $29(42.65 \%)$ & $5(31.25 \%)$ & 34 & \\
\hline & $\mathrm{CCI}=4$ or $4+$ & $36(52.94 \%)$ & $10(62.5 \%)$ & 46 & \\
\hline & $N A$ & 1 & & 1 & \\
\hline \multirow{4}{*}{$\begin{array}{l}\text { Time frame (between onset of complaints } \\
\text { and hospital admission) }\end{array}$} & $0-72 \mathrm{~h}$ & $23(36.51 \%)$ & $6(42.86 \%)$ & 29 & \multirow{4}{*}{$\begin{array}{l}p \text { value }=0.93 \\
\text { Pearson's chi-squared test with simulated } p \\
\text { value (based on } 2000 \text { replicates) }\end{array}$} \\
\hline & $72 \mathrm{~h}-1$ week & $30(47.62 \%)$ & $6(42.86 \%)$ & 36 & \\
\hline & Over 1 week & $10(15.87 \%)$ & $2(14.29 \%)$ & 12 & \\
\hline & $N A$ & 6 & 2 & 8 & \\
\hline \multirow{5}{*}{$\begin{array}{l}\text { Indication of PTGBD based on abdomi- } \\
\text { nal US }\end{array}$} & AAC & $2(2.9 \%)$ & $1(6.25 \%)$ & 3 & \multirow{5}{*}{$\begin{array}{l}p \text { value }=0.7836 \text { Pearson's chi-squared test } \\
\text { with simulated } p \text { value (based on } 2000 \\
\text { replicates) }\end{array}$} \\
\hline & $\mathrm{ACC}$ & $25(36.23 \%)$ & $8(50 \%)$ & 33 & \\
\hline & EVF & $5(7.25 \%)$ & $1(6.25 \%)$ & 6 & \\
\hline & HVF & $16(23.19 \%)$ & $2(12.5 \%)$ & 18 & \\
\hline & PC & $21(30.43 \%)$ & $4(25 \%)$ & 25 & \\
\hline \multirow[t]{3}{*}{ AC severity grade (TG18/TG13) } & I & $9(13.04 \%)$ & $0(0 \%)$ & 9 & $p$ value $=0.0004998$ \\
\hline & II & $56(81.16 \%)$ & $9(56.25 \%)$ & 65 & \multirow[t]{2}{*}{$\begin{array}{l}\text { Pearson's chi-squared test with simulated } p \\
\text { value (based on } 2000 \text { replicates) }\end{array}$} \\
\hline & III & $4(5.8 \%)$ & 7 (43.75\%) & 11 & \\
\hline
\end{tabular}

$A C$ Acute cholecystitis, $A A C$ Acute acalculous cholecystitis, ACC Acute calculous cholecystitis, EVF Empyema vesicae felleae, $H V F$ Hydrops vesicae felleae, $N A$ No data, $P C$ Covered perforated cholecyst, $U S$ Ultrasound

mortality after 563 PTGBDs [24]. Although the guidelines recommend PTGBD for elderly or critically ill patients as well as in grade II-III inflammation [22, 11], mortality of approximately $41 \%$ was observed in grade III inflammation after PTGBD in this study. Based on logistic regression, the severity of inflammation was the most significant factor in patient survival. It should be noted that Sanaiha et al. found significantly lower mortality in grade III inflammation after early LC than in percutaneous cholecystostomy based on a retrospective cohort of 358,624 patients [25]. This further elucidates the role of PTGBD as well as acute or early LC in the complex treatment of grade III AC.

In addition to mortality, the success of PTGBD is demonstrated by the need for emergency CCY, among other treatment options. In a systematic review by Winbladh et al., the frequency of emergency CCY after percutaneous cholecystostomy was found to be between $2 \%$ and $20 \%$ [8]. In our study, emergency CCY was performed in $10 \%$ of the cases.
These surgeries may become necessary when the disease progresses despite PTGBD and antibiotics or general supportive treatment. In the case noted above, extremely difficult surgeries can be expected with a high rate of primary open cholecystectomies (31.25\%) and CR (18.18\%), based on our study. The purpose of timely emergency CCY surgeries is to avoid complications, sepsis and septic shock as much as possible. We have to consider the fact that there is clinical progression after PTGBD in some cases and thus emergency CCY surgery should be performed (9.87\%), which is a critical situation with high overall mortality (14.29\%). In view of these results, the choice of emergency CCY or PTGBD should be considered in AC with grade III inflammation.

Several studies recommend percutaneous cholecystostomy in AAC [26, 27]. We should highlight that almost $56 \%$ mortality was observed after PTGBD among patients with AAC in our study. Due to the low number of cases, we 
Table 6 Survival and in-hospital mortality according to patient and intervention characteristics

\begin{tabular}{|c|c|c|c|c|c|c|c|c|}
\hline Total & & $N$ & & Survival & & In-hospital mortality & NA & $p$ \\
\hline & & 162 & 128 & $(88.28 \%)$ & 17 & $(11.72 \%)$ & 17 & - \\
\hline \multirow[t]{2}{*}{ Age (years) } & $30-65$ & 46 & 36 & $(90.00 \%)$ & 4 & $(10.00 \%)$ & 6 & \multirow[t]{2}{*}{0.7811} \\
\hline & $65+$ & 116 & 92 & $(87.62 \%)$ & 13 & $(12.38 \%)$ & 11 & \\
\hline \multirow[t]{2}{*}{ Sex } & Female & 79 & 58 & $(87.88 \%)$ & 8 & $(12.12 \%)$ & 13 & \multirow[t]{2}{*}{1} \\
\hline & Male & 83 & 70 & $(88.61 \%)$ & 9 & $(11.39 \%)$ & 4 & \\
\hline \multirow[t]{4}{*}{ ASA score } & 1 & 16 & 15 & $(100.00 \%)$ & 0 & $(0.00 \%)$ & 1 & \multirow[t]{4}{*}{$\operatorname{sim} p$ value $=0.001999$} \\
\hline & 2 & 65 & 55 & $(98.21 \%)$ & 1 & $(1.79 \%)$ & 9 & \\
\hline & 3 & 54 & 42 & $(85.71 \%)$ & 7 & $(14.29 \%)$ & 5 & \\
\hline & 4 & 23 & 15 & $(68.18 \%)$ & 7 & $(31.82 \%)$ & 1 & \\
\hline \multirow[t]{4}{*}{$\mathrm{CCI}$} & $\mathrm{CCI}=0$ & 8 & 6 & $(100.00 \%)$ & 0 & $(0.00 \%)$ & 2 & \multirow[t]{4}{*}{$\operatorname{sim} p$ value $=0.02299$} \\
\hline & $\mathrm{CCI}=1-3$ & 46 & 41 & $(100.00 \%)$ & 0 & $(0.00 \%)$ & 5 & \\
\hline & $\mathrm{CCI}=4+$ & 102 & 79 & $(84.04 \%)$ & 15 & $(15.96 \%)$ & 8 & \\
\hline & $N A$ & 6 & & & & & & \\
\hline \multirow{4}{*}{$\begin{array}{l}\text { Time frame (between onset of complaints } \\
\text { and hospital admission) }\end{array}$} & $0-72 \mathrm{~h}$ & 54 & 46 & $(86.79 \%)$ & 7 & $(13.21 \%)$ & 1 & \multirow[t]{4}{*}{$\operatorname{sim} p$ value $=0.1729$} \\
\hline & 3 days -1 week & 62 & 52 & $(96.3 \%)$ & 2 & $(3.70 \%)$ & 3 & \\
\hline & Over 1 week & 20 & 15 & $(88.24 \%)$ & 2 & $(11.76 \%)$ & 8 & \\
\hline & $N A$ & 26 & & & & & & \\
\hline \multirow{5}{*}{$\begin{array}{l}\text { Indication of PTGBD based on abdominal } \\
\text { US }\end{array}$} & $\mathrm{AAC}$ & 9 & 4 & $(44.44 \%)$ & 5 & $(55.56 \%)$ & 0 & \multirow[t]{5}{*}{-} \\
\hline & $\mathrm{ACC}$ & 55 & 47 & $(94.00 \%)$ & 3 & $(6.00 \%)$ & 5 & \\
\hline & EVF & 17 & 11 & $(91.67 \%)$ & 1 & $(8.33 \%)$ & 5 & \\
\hline & HVF & 37 & 30 & $(88.24 \%)$ & 4 & $(11.76 \%)$ & 3 & \\
\hline & $\mathrm{PC}$ & 44 & 36 & $(90.00 \%)$ & 4 & $(10.00 \%)$ & 4 & \\
\hline \multirow[t]{4}{*}{ AC severity grade (TG18/TG13) } & I & 14 & 14 & $(100 \%)$ & 0 & $(0 \%)$ & 0 & \multirow[t]{4}{*}{$\operatorname{sim} p$ value $=0.0004998$} \\
\hline & II & 117 & 100 & $(92.59 \%)$ & 8 & $(7.41 \%)$ & 9 & \\
\hline & III & 28 & 13 & $(59.09 \%)$ & 9 & $(40.91 \%)$ & 6 & \\
\hline & $N A$ & 3 & & & & & & \\
\hline \multirow[t]{2}{*}{ CCY after PTGBD } & Planned & 69 & 66 & $(100 \%)$ & 0 & $(0 \%)$ & 3 & \multirow[t]{2}{*}{0.0288} \\
\hline & Emergency & 16 & 12 & $(85.71 \%)$ & 2 & $(14.29 \%)$ & 2 & \\
\hline
\end{tabular}

$A A C$ Acute acalculous cholecystitis, $A C C$ Acute calculous cholecystitis, EVF Empyema vesicae felleae, $H V F$ Hydrops vesicae felleae, $N A$ No data, PC Covered perforated cholecyst, PTGBD Percutaneous transhepatic gallbladder drainage, TG13/18 Tokyo Guidelines 2013 and 2018 , US Ultrasound (*Fischer's exact test and Pearson's chi-squared test)

Table 7 Logistic regression between negative patient outcomes (in-hospital mortality, clinical progression and emergency cholecystectomy) and patient's performance status or AC severity

\begin{tabular}{|c|c|c|c|c|c|c|c|}
\hline & & B & S.E & df & $P$ & OR $(95 \% \mathrm{CI})$ & Model characteristics \\
\hline \multirow[t]{3}{*}{ In-hospital mortality $N=141$} & CCI & 0.562 & 0.168 & 1 & 0.001 & $1.75(1.26-2.44)$ & \multirow{3}{*}{$\begin{array}{c}\text { Nagelkerke R-squared }=0.345 ; \\
\text { Correct predictions }=87.2 \%\end{array}$} \\
\hline & AC severity grade & 1.803 & 0.623 & 1 & 0.004 & 6.07 (1.79-20.56) & \\
\hline & Constant & -9.154 & 1.955 & 1 & 0.000 & & \\
\hline \multirow{3}{*}{$\begin{array}{l}\text { Clinical progression after PTGBD } \\
\quad N=152\end{array}$} & $\mathrm{CCI}$ & -0.001 & 0.136 & 1 & 0.995 & $1.00(0.77-1.3)$ & \multirow{3}{*}{$\begin{array}{c}\text { Nagelkerke R-squared }=0.199 ; \\
\text { Correct predictions }=87.5 \%\end{array}$} \\
\hline & AC severity grade & 2.031 & 0.542 & 1 & 0.000 & $7.62(2.64-22.05)$ & \\
\hline & Constant & -6.533 & 1.287 & 1 & 0.000 & & \\
\hline \multirow{3}{*}{$\begin{array}{l}\text { Emergency CCY after PTGBD } \\
N=84\end{array}$} & $\mathrm{CCI}$ & -0.124 & 0.182 & 1 & 0.495 & $0.88(0.62-1.26)$ & \multirow{3}{*}{$\begin{array}{c}\text { Nagelkerke R-squared }=0.273 ; \\
\text { Correct predictions }=84.5 \%\end{array}$} \\
\hline & AC severity grade & 2.691 & 0.800 & 1 & 0.001 & $14.75(3.07-70.81)$ & \\
\hline & Constant & -6.812 & 1.611 & 1 & 0.000 & & \\
\hline
\end{tabular}

$A C$ Acute cholecystitis, $B$ Regression coefficient, $C C I$ Charlson comorbidity index, $d f$ Degree of freedom, $O R$ Odds ratio, $C I$ Confidence interval 
have to interpret these results cautiously. However, a similar tendency was reported by Winbladh and his colleagues. In diagnostically uncertain cholecystitis, mortality was significantly higher than in $\mathrm{AC}$ with a clear origin; where the rate of gallstones was lower, mortality was expected to be higher, even up to $40-60 \%$ [8]. The previous observation was supported by a population-based analysis by Schlottmann et al. [28], in which a significantly worse postoperative outcome was observed in AAC than in patients with ACC after 7,516 cholecystostomy tube placement interventions.

Focussing on the proportion of elective cholecystectomies, it appears that cholecystectomy (CCY) was not performed after PTGBD in almost half of the cases (46.94\%). Harai and his colleagues reported a similar trend: no CCY surgery was performed in almost $40 \%$ of cases after PTGBD [29]. Moreover, in a systematic review study of 1,925 patients by Winbladh and his colleagues, the proportion of patients who did not undergo surgery after percutaneous cholecystostomy was $62 \%$ [8]. PTGBD can be considered as a definitive final therapy [30]. This is also confirmed by our results, which showed that elective LCs generally occurred in younger patients $(68.35 \pm 11.34$ years $)$ compared to patients without further elective CCY $(73.39 \pm 15.39$ years). Clarification of the causes of non-occurring $\mathrm{CCY}$ requires further investigation.

Emergency or urgent surgeries were needed in clinical progression and when the patient did not respond well to PTGBD intervention, especially in older patients with poor general condition (with high CCI) diagnosed with severe AC. Based on logistic regression analyses, the level of gallbladder inflammation has been significantly associated with the need for urgent surgery after PTGBD.

In the CRs of surgeries performed with different timings (elective or emergency), there was essentially no difference (17.46\% vs. $18.18 \%)$. A similar result was obtained by $\mathrm{Ni}$ and colleagues [31], who found a conversion rate of $19.2 \%$ in patients who had previously undergone PTGBD. On average, the CR is around 4\% during elective LCs [32, 33], but the CR of acute LC was around 9-10\%. The remarkably high CR of elective LCs after PTGBD may be explained by the fact that these delayed LC surgeries were performed in older patients $(68.35 \pm 11.34$ years), where, in addition to age, gallbladder wall thickening and adhesions from previous inflammation may further increase the chance of conversion. In these cases, it can be very difficult to accurately identify the structures of the Calot triangle that may lead to biliary tract injury. The ratio of major, Strasberg type D bile duct injury may be as high as $9.5 \%[34,35]$. In our study, the BDI ratio during CCY after PTGBD was $1.17 \%$, which is roughly the same as the results reported by Altieri and her colleagues in 2019. According to Altieri, elective CCYs occurred in approximately $30 \%$ of patients after 9,738 PTGBDs, with a BDI rate of approximately $1.6 \%$ [36].
Following PTGBD, a relatively high portion (approximately $15 \%$ of patients) required ERCP. According to the literature, the need for ERCP can reach as high as 40\% [37, 38]. In our study, ERCP was most often indicated due to the non-decreasing amount of bile excreted through the inserted drain. In most of the cases, the result of ERCP was biliary obstruction $\mathrm{BO}$, including choledocholithiasis. We hypothesize that common bile duct stone (CBDS) played an important role in the development of AC in most patients, as AC more easily develops by increasing biliary pressure and interfering with gallbladder emptying. Based on our study, CBDS caused a problem indicating ERCP in approximately $44 \%$ of patients who underwent PTGBD. The importance of CBGS has been highlighted in several reports, including Kuan and her colleagues, who reported a 7-27\% incidence of CBDS following percutaneous cholecystostomy [37, 38]. In mild or complete biliary obstruction, bile is emptied through a drain inserted into the gallbladder due to increased biliary pressure, which in many cases prevents the drain from being removed. Another cause of heavy bile excretion may be minor bile duct injury during a PTGBD procedure; however, no such case was observed in our study. In the light of this, it is recommended that ERCP be performed in cases where biliary excretion does not decrease after PTGBD.

\section{Conclusion}

PTGBD is an easy-to-perform intervention in the treatment of acute cholecystitis with good TSR, with clinical and surgical success influenced by several factors, such as the patient's age and the level of gallbladder inflammation. It is used as a definitive therapy in a significant proportion of patients, while it serves as bridging for other patients before subsequent elective CCY. The level of inflammation plays a crucial role in the course of $\mathrm{AC}$, whereas in severe, grade III inflammation, we have to consider high clinical progression, a high proportion of emergency CCYs and high mortality after PTGBD.

\section{Limitations of the study}

Limitations include retrospective nature of the study, with relative restrictions in patient selection and inclusion. We were unable to identify patients who had died outside our institutions; therefore, we could not determine the exact number and causes of the 30-day and overall mortality. After PTGBD, we were unable to identify the direct causes of the absence of elective CCY, so we can only infer them. 
Funding Open access funding provided by University of Szeged. No funds were received for the current study.

\section{Declarations}

Disclosures Sz Ábrahám, I Tóth, R Benkő, M Matuz, G Kovács, Z Morvay, A Nagy, A Ottlakán, L Czakó, Z Szepes, D Váczi, A Négyessy, A Paszt, Zs Simonka, A Petri and Gy Lázár have no conficts of interest or financial ties to disclose.

Open Access This article is licensed under a Creative Commons Attribution 4.0 International License, which permits use, sharing, adaptation, distribution and reproduction in any medium or format, as long as you give appropriate credit to the original author(s) and the source, provide a link to the Creative Commons licence, and indicate if changes were made. The images or other third party material in this article are included in the article's Creative Commons licence, unless indicated otherwise in a credit line to the material. If material is not included in the article's Creative Commons licence and your intended use is not permitted by statutory regulation or exceeds the permitted use, you will need to obtain permission directly from the copyright holder. To view a copy of this licence, visit http://creativecommons.org/licenses/by/4.0/.

\section{References}

1. Elyaderani M, Gabriele OF (1979) Percutaneous cholecystostomy and cholangiography in patients with obstructive jaundice. Radiology 130:601-602

2. Ito T, Bandai Y, Makuuchi M, Watanabe G, Wada T (1983) Ultrasonographic diagnosis and drainage in noncalculous acute cholecystitis following surgery. Ultrasound Med Biol Suppl 2:471-475

3. Makuuchi M, Bandai Y, Ito T, Watanabe G, Wada T, Abe H, Muroi T (1980) Ultrasonically guided percutaneous transhepatic bile drainage: a single-step procedure without cholangiography. Radiology 136:165-169

4. Makuuchi M, Yamazaki S, Hasegawa H, Bandai Y, Ito T, Watanabe G (1984) Ultrasonically guided cholangiography and bile drainage. Ultrasound Med Biol 10:617-623

5. Olak J, Stein LA, Meakins JL (1986) Palliative percutaneous transhepatic biliary drainage: assessment of morbidity and mortality. Can J Surg 29:243-246

6. Irani S, Ngamruengphong S, Teoh A, Will U, Nieto J, Abu Dayyeh BK, Gan SI, Larsen M, Yip HC, Topazian MD, Levy MJ, Thompson CC, Storm AC, Hajiyeva G, Ismail A, Chen YI, Bukhari M, Chavez YH, Kumbhari V, Khashab MA (2017) Similar efficacies of endoscopic ultrasound gallbladder drainage with a lumenapposing metal stent versus percutaneous transhepatic gallbladder drainage for acute cholecystitis. Clin Gastroenterol Hepatol 15:738-745. https://doi.org/10.1016/j.cgh.2016.12.021 (Epub 2016 Dec 30)

7. Ogura T, Higuchi K (2019) Endoscopic ultrasound-guided gallbladder drainage: current status and future prospects. Dig Endosc 31(Suppl 1):55-64. https://doi.org/10.1111/den.13334.Review (PubMed PMID: 30994239)

8. Winbladh A, Gullstrand P, Svanvik J, Sandström P (2009) Systematic review of cholecystostomy as a treatment option in acute cholecystitis. HPB (Oxford) 11:183-193. https://doi.org/10. $1111 / \mathrm{j} .1477-2574.2009 .00052 . x$

9. Kiviniemi H, Mäkelä JT, Autio R, Tikkakoski T, Leinonen S, Siniluoto T, Perälä J, Päivänsalo M, Merikanto J (1998) Percutaneous cholecystostomy in acute cholecystitis in high-risk patients: an analysis of 69 patients. Int Surg 83:299-302
10. Lee MJ, Saini S, Brink JA, Hahn PF, Simeone JF, Morrison MC, Rattner D, Mueller PR (1991) Treatment of critically ill patients with sepsis of unknown cause: value of percutaneous cholecystostomy. AJR Am J Roentgenol 156:1163-1166

11. Okamoto K, Suzuki K, Takada T, Strasberg SM, Asbun HJ, Endo I, Iwashita Y, Hibi T, Pitt HA, Umezawa A, Asai K, Han HS, Hwang TL, Mori Y, Yoon YS, Huang WS, Belli G, Dervenis C, Yokoe M, Kiriyama S, Itoi T, Jagannath P, Garden OJ, Miura, F, Nakamura M, Horiguchi A, Wakabayashi G, Cherqui D, de Santibañes E, Shikata S, Noguchi Y, Ukai T, Higuchi R, Wada K, Honda G, Supe AN, Yoshida M, Mayumi T, Gouma DJ, Deziel DJ, Liau KH, Chen MF, Shibao K, Liu KH, Su CH, Chan ACW, Yoon, DS, Choi IS, Jonas E, Chen XP, Fan ST, Ker CG, Giménez ME, Kitano S, Inomata M, Hirata K, Inui K, Sumiyama Y, Yamamoto M (2018) Tokyo Guidelines 2018: flowchart for the management of acute cholecystitis. J Hepatobiliary Pancreat Sci 25:55-72. DOI: https://doi.org/10.1002/jhbp.516. Epub 2017 Dec 20. Review. Erratum in: J Hepatobiliary Pancreat Sci (2019) 26:534.

12. Miura F, Takada T, Strasberg SM, Solomkin JS, Pitt HA, Gouma DJ, Garden OJ, Büchler MW, Yoshida M, Mayumi T, Okamoto K, Gomi H, Kusachi S, Kiriyama S, Yokoe M, Kimura Y, Higuchi R, Yamashita Y, Windsor JA, Tsuyuguchi T, Gabata T, Itoi T, Hata J, Liau KH, Committee TGR (2013) TG13 flowchart for the management of acute cholangitis and cholecystitis. J Hepatobiliary Pancreat Sci 20:47-54. https://doi.org/10.1007/s00534-012-0563-1

13. Charlson ME, Pompei P, Ales KL, MacKenzie CR (1987) A new method of classifying prognostic comorbidity in longitudinal studies: development and validation. J Chronic Dis 40:373-383

14. ASA Physical Status Classification System. Last approved by the ASA House of Delegates on October 15, 2014. https://www.asahq. org/resources/clinical-information/asa-physical-status-classifica tion-system. Accessed 26 Jan 2021.

15. Endo I, Takada T, Hwang TL, Akazawa K, Mori R, Miura F, Yokoe M, Itoi T, Gomi, H, Chen MF, Jan YY, Ker CG, Wang HP, Kiriyama S, Wada K, Yamaue H, Miyazaki M, Yamamoto M (2017) Optimal treatment strategy for acute cholecystitis based on predictive factors: Japan-Taiwan multicenter cohort study. J Hepatobiliary Pancreat Sci 24:346-361. DOI: https://doi.org/10. 1002/jhbp.456. Epub 2017 May 31. Erratum in: J Hepatobiliary Pancreat Sci 24:492-493. J Hepatobiliary Pancreat Sci (2018) 25:283-284.

16. Borzellino G, Sauerland S, Minicozzi AM, Verlato G, Di Pietrantonj C, de Manzoni G, Cordiano C (2008) Laparoscopic cholecystectomy for severe acute cholecystitis. A meta-analysis of results Surg Endosc 22:8-15 (Epub 2007 Aug 18)

17. Loozen CS, van Ramshorst B, van Santvoort HC, Boerma D (2017) Early cholecystectomy for acute cholecystitis in the elderly population: a systematic review and meta-analysis. Dig Surg 34:371-379. https://doi.org/10.1159/000455241 (Epub 2017 Jan 18)

18. Takada T, Kawarada Y, Nimura Y, Yoshida M, Mayumi T, Sekimoto M, Miura F, Wada K, Hirota M, Yamashita Y, Nagino M, Tsuyuguchi T, Tanaka A, Kimura Y, Yasuda H, Hirata K, Pitt HA, Strasberg SM, Gadacz TR, Bornman PC, Gouma DJ, Belli G, Liau KH (2007) Background: Tokyo guidelines for the management of acute cholangitis and cholecystitis. J Hepatobiliary Pancreat Surg 14:1-10. https://doi.org/10.1007/s00534-006-1150-0 (Epub 2007 Jan 30)

19. Yokoe M, Hata J, Takada T, Strasberg SM, Asbun HJ, Wakabayashi G, Kozaka K, Endo I, Deziel DJ, Miura F, Okamoto K, Hwang TL, Huang WSW, Ker CG, Chen MF, Han HS, Yoon YS, Choi IS, Yoon DS, Noguchi Y, Shikata S, Ukai T, Higuchi R, Gabata T, Mori Y, Iwashita Y, Hibi T, Jagannath P, Jonas E, Liau KH, Dervenis C, Gouma DJ, Cherqui D, Belli G, Garden OJ, Giménez ME, de Santibañes E, Suzuki K, Umezawa A, Supe AN, 
Pitt HA, Singh H, Chan ACW, Lau WY, Teoh AYB, Honda G, Sugioka A, Asai K, Gomi H, Itoi T, Kiriyama S, Yoshida M, Mayumi T, Matsumura N, Tokumura H, Kitano S, Hirata K, Inui K, Sumiyama Y, Yamamoto M (2018) Tokyo Guidelines 2018: diagnostic criteria and severity grading of acute cholecystitis (with videos). J Hepatobiliary Pancreat Sci 25:41-54. https://doi.org/10. $1002 / \mathrm{jhbp} .515$

20. Anderson BB, Nazem A (1987) Perforations of the gallbladder and cholecystobiliary fistulae: a review of management and a new classification. J Natl Med Assoc 79:393-399

21. Kiss J, Bohák A, Vörös A, Szirányi E (1988) The role of ultrasound-guided percutaneous transhepatic aspiration of the gallbladder content in the management of hydrops/empyema caused by acute cholecystitis. Int Surg 73:35-37

22. Pisano M, Ceresoli M, Cimbanassi S, Gurusamy K, Coccolini F, Borzellino G, Costa G, Allievi N, Amato B, Boerma D, Calcagno P, Campanati L, Campanile FC, Casati A, Chiara O, Crucitti A, di Saverio S, Filauro M, Gabrielli F, Guttadauro A, Kluger Y, Magnone S, Merli C, Poiasina E, Puzziello A, Sartelli M, Catena F, Ansaloni L (2019) 2017 WSES and SICG guidelines on acute calcolous cholecystitis in elderly population. World J Emerg Surg 14:10. https://doi.org/10.1186/s13017-019-0224-7

23. Yokoe M, Takada T, Hwang TL, Endo I, Akazawa K, Miura F, Mayumi T, Mori R, Chen MF, Jan YY, Ker CG, Wang HP, Itoi T, Gomi H, Kiriyama S, Wada K, Yamaue H, Miyazaki M, Yamamoto M (2017) Validation of TG13 severity grading in acute cholecystitis: Japan-Taiwan collaborative study for acute cholecystitis. J Hepatobiliary Pancreat Sci 24:338-345. https://doi.org/10.1002/ jhbp. 457

24. Dimou FM, Adhikari D, Mehta HB, Riall TS (2017) Outcomes in older patients with grade III cholecystitis and cholecystostomy tube placement: a propensity score analysis. J Am Coll Surg 224:502-511.e1. https://doi.org/10.1016/j.jamcollsurg.2016.12. 021 (Epub 2017 Jan 6)

25. Sanaiha Y, Juo YY, Rudasill SE, Jaman R, Sareh S, de Virgilio C, Benharash P (2020) Percutaneous cholecystostomy for grade III acute cholecystitis is associated with worse outcomes. Am J Surg 220:197-202. https://doi.org/10.1016/j.amjsurg.2019.11.025

26. Noh SY, Gwon DI, Ko GY, Yoon HK, Sung KB (2018) Role of percutaneous cholecystostomy for acute acalculous cholecystitis: clinical outcomes of 271 patients. Eur Radiol 28:1449-1455. https://doi.org/10.1007/s00330-017-5112-5 (Epub 2017 Nov 7)

27. Kirkegård J, Horn T, Christensen SD, Larsen LP, Knudsen AR, Mortensen FV (2015) Percutaneous cholecystostomy is an effective definitive treatment option for acute acalculous cholecystitis. Scand J Surg 104:238-243. https://doi.org/10.1177/1457496914 564107 (Epub 2015 Jan 7)

28. Schlottmann F, Gaber C, Strassle PD, Patti MG, Charles AG (2019) Cholecystectomy vs. cholecystostomy for the management of acute cholecystitis in elderly patients. J Gastrointest Surg 23:503-509. https://doi.org/10.1007/s11605-018-3863-1 (Epub 2018 Sep 17)
29. Harai S, Mochizuki H, Kojima Y, Nakagomi K, Yoshimura D, Takaoka S, Hosoda K, Suzuki Y, Omata M (2019) Validation of Tokyo guideline 2013 as treatment of acute cholecystitis by Real World Data. Dig Dis 37:303-308. https://doi.org/10.1159/00049 6738 (Epub 2019 Feb 7)

30. Li M, Li N, Ji W, Quan Z, Wan X, Wu X, Li J (2013) Percutaneous cholecystostomy is a definitive treatment for acute cholecystitis in elderly high-risk patients. Am Surg 79:524-527

31. Ni Q, Chen D, Xu R, Shang D (2015) The efficacy of percutaneous transhepatic gallbladder drainage on acute cholecystitis in highrisk elderly patients based on the Tokyo Guidelines: a retrospective case-control study. Medicine (Baltimore) 94:e1442. https:// doi.org/10.1097/MD.0000000000001442

32. Sutcliffe RP, Hollyman M, Hodson J, Bonney G, Vohra RS, Griffiths EA, CholeS study group, West Midlands Research Collaborative (2016) Preoperative risk factors for conversion from laparoscopic to open cholecystectomy: a validated risk score derived from a prospective UK database of 8820 patients. HPB (Oxford) 18:922-928. https://doi.org/10.1016/j.hpb.2016.07.015 (Epub 2016 Aug 31)

33. Ballal M, David G, Willmott S, Corless DJ, Deakin M, Slavin JP (2009) Conversion after laparoscopic cholecystectomy in England. Surg Endosc 23:2338-2344. https://doi.org/10.1007/s00464-0090338-1 (Epub 2009 Mar 6)

34. Lin D, Wu S, Fan Y, Ke C (2019) Comparison of laparoscopic cholecystectomy and delayed laparoscopic cholecystectomy in aged acute calculous cholecystitis: a cohort study. Surg Endosc. https://doi.org/10.1007/s00464-019-07091-4 (Epub ahead of print)

35. Strasberg SM, Hertl M, Soper NJ (1995) An analysis of the problem of biliary injury during laparoscopic cholecystectomy. J Am Coll Surg 180:101-125

36. Altieri MS, Bevilacqua L, Yang J, Yin D, Docimo S, Spaniolas K, Talamini M, Pryor A (2019) Cholecystectomy following percutaneous cholecystostomy tube placement leads to higher rate of CBD injuries. Surg Endosc 33:2686-2690. https://doi.org/10. 1007/s00464-018-6559-4 (Epub 2018 Nov 26)

37. Kuan LL, Oyebola T, Mavilakandy A, Dennison AR, Garcea G (2020) Retrospective analysis of outcomes following percutaneous cholecystostomy for acute cholecystitis. World J Surg. https://doi. org/10.1007/s00268-020-05491-5 (Epub ahead of print)

38. Furtado R, Le Page P, Dunn G, Falk GL (2016) High rate of common bile duct stones and postoperative abscess following percutaneous cholecystostomy. Ann R Coll Surg Engl 98:102-106. https://doi.org/10.1308/rcsann.2016.0004 (Epub 2016 Jan 7)

Publisher's Note Springer Nature remains neutral with regard to jurisdictional claims in published maps and institutional affiliations. 